\title{
Time in Language, Language in Time
}

\author{
Wolfgang Klein
}

Max Planck Institute for Psycholinguistics

\section{The Linguist's Daily Bread}

Many millenia ago, a number of genetic changes endowed our species with the remarkable capacity

- to construct highly complex systems of expressions - human languages;

- to copy such systems, once created, from other members of the species;

- to use them for communicative and perhaps other purposes.

This capacity is not uniform; it is actually a set of interacting capacities, which are rooted somewhere in the brain of the individual. However, each of the three processes made possible by this set of capacities also involves social interaction with other individuals. The creation of a language, its acquisition - be it as a child or as an adult - as well as its use in communication are fundamentally social in nature. We do not know how the first language came into existence. However, it is not very likely that a particularly gifted member of our species thought it out and then passed it on to his or her family and some of his or her best friends; languages grow in steady interaction among humans. The creation of, acquisition of, and communication by means of a linguistic system are processes that have a biological as well as a social side. The tradition of linguistic research from antiquity to the end of the 20th century has always been aware of these two dimensions. What it has been much less aware of is their temporal side. What linguists normally care for is not so much the properties of the three processes but the properties of the products that they bring forth. Linguists try to uncover the characteristics of linguistic systems

Pages 1 to 8 of this article are a somewhat expanded version of my introduction to the round table. The remainder is (with minimal changes) the brief text that was sent in advance to the participants of the round table on which this volume is based.

Correspondence concerning this article should be addressed to Wolfgang Klein, Max Planck Institute for Psycholinguistics, P.O. Box 310, 6500 AH Nijmegen, The Netherlands. Internet: wolfgang.klein@mpi.nl 
(i.e., of what the ensemble of our genetically given language capacities have brought forth in social interaction) and they try to understand the properties of the utterances (i.e., of what these systems, in turn, bring forth when put to use in a concrete situation). Thus, linguists normally deal with the lexical or grammatical features of Greek or Tagalog, and they deal with the structural and functional characteristics of a sentence or a text in these languages. Both tasks - in Saussure's terms, la linguistique de la langue and la linguistique de la parole - are closely linked to each other. In fact, the second task is most often seen as somehow subordinate to the first task: The properties of a particular utterance are often not studied in their own right but in order to find out the properties of the underlying system. This preference is clearly stated in the famous last sentence of Ferdinand de Saussure's Cours de linguistique générale (1917): "La linguistique a pour unique et véritable objet la langue envisagée en elle-même et pour elle-même" (The unique and true object of linguistics is language viewed in and for itself). We now know that this sentence is not by Saussure himself but was added by the editors. However, it is true that for most linguists, the "language as such" is the primary object of concrete work. They look at a structure, not at a process, and even if they study concrete utterances that are deployed in time, they are interested in their grammatical and lexical properties, not in the way in which they are produced or understood in real time. Traditional linguistics is mostly time-free.

This picture of the tradition is simplified on a number of grounds. First, from Herakleitos to Chomsky, there has always been a strong interest in what is common to all human languages - in universal grammar — and, second, parallel to this concern, in how these linguistic universals relate to other capacities of the human mind - in particular, to what is called thinking. Third, many have been and are fascinated by the question of "the origin of language." Herodotos tells the story of the Egyptian king Psammetikh who let a newborn grow up without any linguistic input in order to find out what the "original language" is (it is Phrygian). Fourth, there has always been considerable interest in the principles of efficient communication and, thus, in the social side of the language capacities. Fifth, toward the second half of the 18th century, linguists also became interested in the way in which linguistic systems change over time (i.e., in a special type of linguistic process). However, the three first issuesuniversal grammar, the relationship between language and thought, and the origin of language - have primarily been topics of - sometimes wild, sometimes intriguing - philosophical speculation, rather than of solid, fact-based research. The fourth issue - the role of language for efficient communication - has primarily been a challenge to teachers of rhetoric and, later, to social psychologists. 
None of these concerns have been at the very heart of what language experts do in their daily work. This is different for the fifth issue - the interest in the history of languages. In fact, historical considerations have ruled the field for at least one century; but historical linguistics had its culminating point around a century ago, and it is now almost a niche within the wider field of language studies. I will come back to this in a moment.

In a nutshell, what linguists have done and still mainly do is to analyze grammatical structures and lexical meanings. They write (parts of) grammars and they compile (parts of) dictionaries. In both cases, this work may include diachronic aspects. Thus, linguists are typically concerned with questions like the following:

(1) 1. What is the position of the verb in English, compared to the verb position in Latin or Turkish?

2. What is the meaning of to eat, compared to the meaning of to drink?

3. What is the meaning of the, compared to the meaning of this or of $a$ ?

4. What is the meaning of still, compared to the meaning of already?

5. What is the difference among He is running, he was running, he ran, he has run, and he has been running?

6. How does the meaning of He was still eating the soup result from the meaning of its parts?

Questions of this type are typical, they are straightforward, and they are the kind of questions the ordinary person expects a linguist to be able to answer. One might assume, therefore, that after so much research - thousands of publications dealing with them appear year after year-linguists are able to do that. However, in actual fact, we know remarkably little about the lexical and grammatical properties of human languages. At present, there are about 6,000-8,000 languages on Earth; it is impossible to give a precise figure, first because there are no clear boundaries between languages and dialects and, second, because most of them have never been studied in any depth. If we qualify a language as well described if there are at least three grammars and three dictionariesa very modest criterion by any standard - then maximally $3 \%$ of the world's languages are well described. About those, we surely know a lot. However, if you look at what even the best available dictionaries of English say about the meaning of familiar items such as to drink, the, or still, you may begin to wonder whether the most common words of the best studied language on Earth are well described.

The reasons for this slightly humiliating state of affairs are, on one hand, the enormous complexity of any human language and, on the other hand, certain 
limitations of the methods that are normally used to analyze the grammatical and lexical properties of such a language. English, for example, has at least 300,000 lexical items such as eat, drink, the, still, or this, and many of these items have a whole range of meanings (as any look in a comprehensive dictionary immediately demonstrates). Suppose that a lexicographer needs one day to describe the lexical meaning(s) of such an item. Then it would take him or her about 1,500 years of work to describe the vocabulary of English, a never-ending task. The second problem, the scarcity of analytic tools, is no less difficult to overcome. Practically all claims about the lexical and grammatical features of a human language are based on two elementary methods that are typically used in combination with each other:

- looking at specimens of actual language production, usually written or spoken (and then transcribed) sentences;

- appealing to the linguistic intuitions of someone who speaks the language (very often the linguist himself or herself); this appeal can have the form of a grammaticality judgment (e.g., Can you say that in Inuktitut?) or a question about the meaning (e.g., What do you use this word for?).

Take, for example, the first of the six questions mentioned above: What is the position of the verb in English, compared to Latin or Turkish? The usual way to answer such a question is to look at a corpus of sample sentences. An initial inspection of such a corpus shows that the position of the verb in Latin is relatively free; it can appear at the beginning, at the end, and somewhere in between. In Turkish, it is predominantly at the end, although other positions are found as well. In English, it also appears in various positions: John closed the window. Did John close the window? Close the window, John! Other positions are not observed; no one seems to say John the window closed. Both findingsthe positions that are observed in the data and the positions that are not observed in the data-are not fully satisfactory to answer the question. It could be accidental that certain positions are not observed (especially if the corpus of sample sentences is small). Additionally, as to the positions that are in fact observed, they yield a somewhat inconsistent picture. It is easy to see that the various positions are not random but correlate somehow with functional differences. However, what are these differences? Here, the linguist appeals to the intuitions of someone who speaks the language. In this particular example, one might be able to correlate varying positions with varying types of speech situations in which the utterance is used and then relate the different positions to different functions. 
Such an observational approach is hardly possible when it comes to lexical meaning. In theory, one might try to determine the meaning of to eat or to drink by observing all types of situations in which these words are used by someone. However, first, this is practically impossible if more than a few words are to be described: It would take 15,000 rather than 1,500 years to describe the vocabulary of English. Second, it is not very telling, because one cannot easily determine which aspect of the situation is related to that particular word. Third, it is plainly impossible for words such as the, still, or or. In practice, and sometimes in principle, there is so far no other way than to appeal to the intuitions of a competent speaker of the language in question; this appeal is supported by the clever use of specimens of the language when used in production. This applies to the determination of lexical meaning; it applies to the determination of syntactic or morphological properties; it applies to the way in which the meaning of compound constructions results from the meaning of its elements.

This is not nice. Is there any way, any instrument, any measurement, or any procedure that would allow us to go substantially beyond what these two methods can provide us? So far, no one has found such a method. However, there are two interconnected developments which raise hopes.

\section{Language in Time}

The first of these developments is what one might call the "discovery of the time dimension." Ever since Aristotle, linguists have been aware of the fact that human languages allow their speakers to express time - for example by the inflectional morphology of the verb ("tense") or by adverbials; we will come back to this in the next section. However, they have hardly considered the fact that language itself is crucially "in time." The average linguist used to see, and still sees, a language as a static system. However, what is so special about the zoon logon echon "the word-bearing animal" are certain properties of the brain (and, to a lesser extent, peripheral organs) that allow him to create such systems, to copy them from others, and to use them for various other purposes. These are processes that go on in time, and if one wants to understand the linguistic nature of humans, one must also look at these processes, and more generally speaking, one must also look at the dynamic side of language. This was hardly done before the end of the 18th century. In that regard, the scientific study of language was not very different from any other area of scientific study. Up to that time, the way in which things evolve over time played a very limited role in the eye of the researcher. This has changed in many disciplines; biology and 
geography are well-known cases. It has also changed for the study of language; in fact, this field may be the first in which this development played a crucial role. Although the study of "time-less" properties of the linguistic system is still the daily bread of the linguist, there are now at least three areas that are devoted to the study of "language in time":

- historical linguistics, which looks at the way in which the lexicon and the grammar of a system change over time;

- language acquisition, which looks at the development of language in the individual;

- language processing, which studies the actual time course of how utterances are produced and understood.

Historical linguistics is a child of the late 18th century; it grew rapidly, and within a century, it was firmly established as the scientific way of studying human language. In the preface to the second edition of his Principien der Sprachgeschichte (1886), Hermann Paul, not only a leading historical linguist but also a brillant theorist, bluntly denied that there could be any other truly scientific study of language than from a historical point of view. The reason was not that he loved the past more than the present but that without history, all we have are isolated facts. The inner connection between these facts becomes clear only when we look at history. It is the same line of reasoning that we find in the theory of biological evolution: Facts only make sense in light of development over time. In linguistics, this position did not prevail. One of the reasons is surely that we have so little evidence of earlier stages of languages. Normally, linguistic features develop slowly; but there are at most two dozen or so languages for which we have good records over more than a thousand years. So, most linguistic work nowadays is not, and simply cannot be, concerned with diachronic aspects. Historical linguistics somehow resembles a spectacular building erected within a century, on which currently much less is and can be built unless new material is discovered.

The scientific study of language acquisition and of language processing is much younger. There are - as always - admirable precursors in the 19th century (and maybe even before that); but only in the last five decades have these complex processes become a subject of intensive and systematic scientific investigation, largely under the label of "psycholinguistics." It is interesting to note that the initial incentive came primarily from psychologists, rather than from linguists, although both areas were fed by linguistic theories - in particular, by generative grammar. Currently, research in both fields is firmly 
established and fertile, and although it is perhaps fair to state that we are still far from fully understanding either, we know much more than one could have hoped for half a century ago.

The second important development is the advent of new methods that came with the study of language acquisition and language processing. Historical linguistics, by its very nature, is largely bound to the two classical methods mentioned in the previous section, namely looking at samples of written utterances and, albeit to a much lesser extent, appeal to intuitions. The latter may sound somewhat surprising; we have no native surviving speakers of Hittite or Tocharic B to consult. However, in fact, the linguist herself, when studying the remaining texts, to some extent becomes a speaker of these languages - with shaky intuitions perhaps, but sufficient to understand the meaning of words and constructions. Otherwise, historical linguistics would be impossible.

Thus, the study of how languages evolve over time did not augment the linguistic tool box. The study of language acquisition and of language processing did. Over the years, numerous experimental designs have been invented and successfully applied. They range from by now "classical" reaction time experiments to the most recent, and most spectacular, techniques of registering physiological processes in the human brain. In a way, the situation is reminiscent of what happened in the sciences, whose eminent progress is largely the result of new instruments and methods - the microscope, the telescope, spectral analysis, X-ray crystallography, and so forth. A great deal of what we now know about how humans produce and understand language would simply have been impossible without the new tools. The progress is perhaps a bit less obvious in language acqusition, where corpus analysis, combined with appeal to intuitions, is still the dominant way to proceed; but here too, experimental methods are steadily gaining ground.

What do these two developments in the study of human language - the turn toward temporal characteristics and the use of new methods - mean for the classical question of linguistic research: What are the grammatical and lexical properties of languages? A brief look at the development in the last few decades rapidly shows that many linguists are genuinely interested in questions of acquisition and processing. However, they only marginally relate them to their own work. I am not aware of any grammatical description or of any lexical analysis that has been substantially influenced by results from psycholinguistics. Sometimes, especially in the generative tradition, linguistic claims are tested against acquisition or processing evidence. However, I am not aware of any case in which conflicting evidence has led to a change of these claims. As a rule, psycholinguistic evidence is only mentioned when it supports 
the linguistic analysis, as gained by the classical methods. However, even those cases are quite rare.

The reason is not just human weakness - who wants to be refuted by evidence from some other field? It is simply that in many cases, one cannot easily tell how the "classical questions," such as exemplified in (1), can be approached by new methods. Can a reaction time experiment help us to decide what the verb position in English is? If fMRI studies show us convincingly that the lexical item to drink is stored in Brodmann's area 44, whereas the lexical item to eat is stored in Brodmann's area 45, what does this tell us about the meaning of these words? It is not the kind of information that you want to hear when you learn English. If acquisition studies demonstrate that children first learn the determiner $a$ and only then the determiner the, whereas the demonstrative this comes last, what does this tell us about the syntactic and semantic properties of these little words? The answer in all of these cases is probably "not very much."

That is not encouraging. However, maybe we have not looked at these problems from the right angle, and we should not only think about how we can use new methods for old questions but rather change our way of thinking about these old problems. Our ideas of what linguistic systems are like are based on the two classical methods that we used to analyze them. New methods (those that include the time dimension of human language) might also be a chance to think in a new way about the properties of these systems.

In doing so, it would perhaps be wise not to begin with questions like those under (1), for which such a potential change in approaching the classical tasks seems particularly far-fetched. A better candidate might be the way in which time and temporal properties themselves are encoded in human languages. The reason is that time and its expression in language is fundamental to human cognition in general. Here, we have a natural relation between an important property of all known human languages, as conceived in the classical way, and the biological and social makeup of the human mind in general. In the next section, I will try to summarize the traditional picture of "time in language." At least for some languages, we know much about how the expression of time works. However, there are still many open questions. Can new methods, new tools, new ways to think about them help us find better answers?

\section{Time in Language}

Time is a fundamental concept of human cognition and action. It is not surprising, therefore, that all languages we know of have developed rich means to 
express the various facets of time: bare time spans, their position on the time line or their duration; "real" events that are actually experienced; imaginary events that could or should happen; events stored in memory, regardless of from which source; and specific temporal features of all of these types of events, such as length of duration or frequency. All of this must somehow be processed in the brain. In what follows, I will first sketch some basic ingredients of time expressions, as linguists understand them, and then raise a few questions at the crossroads of language, cognition beyond language, and brain.

\section{Background}

Roughly, there are six main devices to encode time in natural language:

A. Tense. Tense is an inflectional category of the verb (often in combination with an auxiliary); in its simplest understanding, it indicates a temporal relation ("earlier," "simultaneous," "later") between some event or state and some "temporal anchor," typically the moment of speech. There are many refinements, such as different types of simultaneity, or degrees of remoteness; these vary from language to language. Tense is not found in all languages, although all languages allow reference to present, past, and future.

B. (Grammatical) Aspect. Aspect is also an inflectional category of the verb (again often in combination with an auxiliary). In its simplest understanding, it indicates a particular viewpoint on the event: The speaker may "show" it as ongoing (imperfective) or as completed (perfective). As a grammatical category, it is as least as frequent as tense, with which it is often combined.

C. "Aktionsarten" (Event Types, Lexical Aspect). Events, as encoded in the verb meaning, differ by various temporal characteristics: They may involve end points or not; they express inherent changes or not; they may last for some time or be punctual; and so forth. Accordingly, we distinguish among processes, actions, events, states, and so forth. Distinctions of this sort are found in all languages.

D. Temporal Adverbials. This is by far the richest category of temporal expressions. Structurally, there are different types: bare adverbs such as now, later, then, shortly, and often; prepositional phrases such as after the autopsy, over the years, at first sight, for three hours, and so forth; or subordinate clauses, such as when the saints are marching in, before I come to the end, and so forth. Functionally, temporal adverbials can express the position of some event on the time line, its duration, and its frequency.

E. Temporal Particles. Some languages (e.g., Chinese) use special particles to express temporality. Although this is somewhat rare, most languages have a 
type of expression that is somehow between particles and temporal adverbs, such as still, yet, and again.

F. Discourse Principles. The construction of texts typically follows certain temporal constraints, the best known of which is the "principle of chronological order": "Unless marked otherwise, the order of mention corresponds to the order of events." Thus, a sentence such as He fell asleep and switched the light off sounds distinctly odd because it violates this principle.

The literature on these issues is vast and impressive. Still, there are many gaps and shortcomings. In particular, we have the following:

(a) Research is strongly biased toward certain devices: By far most studies deal with the "verb devices" (i.e., tense, aspect, and Aktionsarten). There is much less work on temporal adverbials, particles, or discourse principles.

(b) Similarly, it is strongly biased toward certain languages: most work deals with the "classical" languages, such as Greek, Latin, English, or Russian. For most of the world's languages, we have only vague ideas in this regard.

(c) It is strongly biased toward certain text types; most work deals with singular events in narratives. Other discourse types, if dealt with at all, are analyzed against this background.

(d) There is little agreement on many fundamental issues, such as the very notions tense and aspect.

\section{The Questions}

A. How do our notions of time and our ways to express them change over the life span?

It is obvious that children have to learn both the underlying concepts as well as the particular means to express them in their mother tongue. However, there is also some reason to assume that older people have different ways to talk about time than younger people.

\section{B. How culture-specific are our notions of time?}

Clearly, temporality is to some extent culture-specific. Calendric time, so important in our everyday life, is very rudimentary, or not found at all, in many cultures. The issue is therefore how "deeply" such differences are rooted in human cognition, whether they are determined or at least influenced by the structure of the language and whether they lead to different processing in the brain. 
C. How is the expression of time connected to the expression of other conceptual categories?

Temporal expressions are often not just temporal. They may also encode, for example, evidentiality, likelihood, or causality. Thus,

- if an event is said to be have happened in the past, speakers often mark, or must mark, whether they have experienced it themselves or whether they know it from hearsay;

- if an event is placed into the future, then this statement often has a modal component: it is likely, but not certain, that it will happen;

- if event $\mathrm{A}$ is said to be after $\mathrm{B}$, then $\mathrm{B}$ is often considered to be the cause of A (post hoc-propter hoc).

D. If an event is located in time, then this can be done in relation to the speech act ("deictic"), in relation to some other event given in discourse ("anaphoric"), or in relation to some culturally important event ("calendric"). How is this difference reflected in other domains of cognition, and how is it reflected in the brain?

The different "anchor points" come from different types of knowledge; the deictic anchor comes from perception, the anaphoric anchor comes from short-term memory in text processing, and the calendric anchor stems from overarching cultural knowledge (the birth of Christ, the Hedjra, etc.). It cannot therefore simply be an issue of language.

F. How do the various devices, in particular marking on the verb and temporal adverbials, interact?

There are redundancies, as in He departed yesterday at four, where the past tense marking is vague and superfluous. There are incompatibilities, as in $\mathrm{He}$ has departed yesterday at four, where the time of the departure is clearly in the past, but one is not allowed to specify this time by an adverbial. Additionally, there are very complex interactions, as becomes clear from the difference between Yesterday at four, he had departed versus He had departed yesterday at four.

G. How does temporality function in other text types, such as descriptions, instructions, film retellings, and legal texts?

In all of these texts, we find temporal markings of all sorts. However, it often makes no sense to talk about deictic anchoring or a particular perspective on the "event." 
H. How are violations within the overall expression of time handled?

Such violations are, for example, the combination of a future time adverbial with a past tense form, as in Tomorrow, I came. Under specific conditions, these combinations are tolerated, as in the famous "epic preterite" Morgen war Weihnachten, und er hatte noch keine Geschenke (tomorrow was Christmas, and he still had no gifts). Similarly, there are deviations from the normal temporal organization of texts, as determined by the "principle of chronological order" and related constraints. Somehow, these violations are either felt to be nonsense or they require a kind of reinterpretation. Either process must have counterparts in the way in which the brain interprets these structures.

\section{A Concluding Remark}

As a linguist who has worked a lot on the expression of time in language and on the way in which learners acquire the relevant devices in a new system, I am quite skeptical that new methods, as the ones mentioned in the section Language in Time, can help us answer these and similar questions. However, it would be arrogant to say that it is impossible, and it is surely worth trying. In the words of Pliny: Quam multa fieri non posse, priusquam sint facta, iudicantur (How many things were not considered impossible before they happened). 